\title{
Effect of Magnesium Sulfate on Mitochondrial Oxygen Consumption Rate In vitro Study
}

\author{
Amna Al Zaabi and Aiman Al-Rahmani*
}

Department of Pediatrics, Tawam Hospital, Al Ain, United Arab Emirates

\begin{abstract}
Hypoxic insults initiate a cascade of biochemical events that result in irreversible neuronal damage. Magnesium sulfate agent has a possible neuroprotective effect as it can work at different stages of hypoxic brain injury.

Objectives: Magnesium sulfate is used in the neonatal management of HIE as an adjunct medication to reduce Hypoxic Neuronal injury. In this Vitro study, we aimed to examine the efficacy of using magnesium sulfate in human cells to reduce oxygen consumption. We used in-vitro method utilizing foreskin as human cell surrogate.

Method: Foreskin specimens from healthy newborns were collected immediately after circumcision and processed within $1 \mathrm{~h}$ for measuring the cellular rate of $\mathrm{O}_{2}$ consumption. Samples were placed in the oxygen phosphorescence analyzer and allowed to run for approximately $1 \mathrm{~h}$. Injection then added magnesium sulfate at different doses into the vial. We analyze the $\mathrm{O}_{2}$ consumption in the samples at different levels of Magnesium Sulfate; the results were plotted using Kaleida Graph TM software.
\end{abstract}

Results: The rate of respiration reduced with increasing the dose of MgSo4. The Cumulative analysis of cellular respiration rate was before and after an addition of $\mathrm{MgSO}_{4}$. Collectively yielding a $(k)$ value of $0.08 \mu \mathrm{M} \mathrm{O}_{2} / \mathrm{min} \mu \mathrm{M} \mathrm{O}$

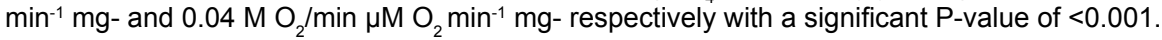

Conclusion: Magnesium sulfate reduces the rate of $\mathrm{O}_{2}$ Consumption in a dose-dependent manner.

Keywords: $\mathrm{O}_{2}$ Consumption; Cellular respiration; Bioenergetics; Metabolism; Mitochondrial; Magnesium sulfate; Perinatal asphyxia; Neonates

Abbreviations: Pd phosphor: Pd (II) complex of meso-tetra-(4sulfonatophenyl)-tetrabenzoporphyrin; PBS: Phosphate-buffered saline; $1 / \tau$ : Phosphorescence Decay Rate; $\mathrm{k}_{\mathrm{q}}$ : The Second-order $\mathrm{O}_{2}$ Quenching Rate Constant in $\sec ^{-1} \mu \mathrm{M}^{-1}$; $\mathrm{k}$ : Rate of Cellular Respiration $\left(\mu \mathrm{M} \mathrm{O}_{2} \min ^{-1}\right) ; \mathrm{k}_{c}$ : Rate of Cellular Respiration Corrected by Specimen Weight $\left(\mu \mathrm{M} \mathrm{O}_{2} \mathrm{~min}^{-1} \mathrm{mg}^{-1}\right) ; \mathrm{MgSO}_{4}$ : Magnesium Sulfate.

\section{Background}

Brain Injury in Neonates can commonly be the result of perinatal hypoxic-ischemic encephalopathy (HIE), which may lead to significant morbidity or death in the newborn period. The injury to the brain occurs as a result of a combination of systemic hypoxemia; which refers to a compromised arterial oxygen concentration. In addition to a diminished cerebra [1] perfusion that leads to ischemia or insufficient blood flow to the cells to maintain their normal function. The pathogenesis of HIE is an integral sequence of cerebral insults that occur initially with hypoxemia, ischemia and next by oxygenation and reperfusion of the ischemic tissue. Perinatal hypoxia is multi-system organ damage with significant impairments in clotting, renal, and cardiac functions. Magnesium Neuroprotection properties are the results of blocking $\mathrm{N}$-methyl-D-aspartate (NMDA) receptor-mediated calcium entry into the cell. Suppress the release of a neurotransmitter that activated by hypoxia [2] and modulating the actions of pro-inflammatory cytokines and oxygen free radicals.

Antenatal magnesium sulfate is one of the known strategies to reduce perinatal cerebral injury and act as Neuroprotection via several pathways [3,4]. Postnatal $\mathrm{MgSO}_{4}$ treatment of severe perinatal asphyxia patients was shown in several studies to improve neurological outcomes at discharge for term neonates compared to control patients [5]. Metaanalysis of high quality randomizes studies demonstrate that the risk of cerebral palsy is reduced to almost one-third in an infant who received antenatal magnesium sulfate [6].

Furthermore, providing Magnesium sulfate treatment was demonstrated to alter fetal cerebellar gene expression in response to hypoxia that known to contribute to cell death and neurogenesis [7]. These changes negatively affected the newborns for that some studies failed to prove the Neuroprotective effect of $\mathrm{MgSO}_{4}$, which may be due to the dual reaction to the $\mathrm{MgSO}_{4}$ treatment in observations reported for affected newborns [8]. The goal was to conduct in vitro study to investigate the effect of magnesium sulfate on metabolic rate and oxygen consumption in human cells using foreskin as a surrogate biomarker for metabolic rate [9-12].

\section{Methods}

\section{Reagents and solutions}

Pd (II) complex of meso-tetra-(4-sulfonatophenyl)-tetra benzoporphyrin (Pd phosphor) obtained from Porphyrin Products (Logan, UT). Minimum Essential Medium (MEM Alpha Modification) was purchased from Gibco (labeled as MEM). Phosphate-buffered saline (PBS), glucose oxidase (powder from Aspergillus niger), D (+) glucose anhydrous and remaining reagents were purchased from Sigma-Tau Pharmaceuticals (Gaithersburg, MD, USA).

*Corresponding author: Aiman Al-Rahmani, Department of Pediatrics, Tawam Hospital, Al Ain, United Arab Emirates, Tel: +97137677435; E-mail: arahmani@seha.ae

Received March 20, 2018; Accepted April 13, 2018; Published April 20, 2018

Citation: Al Zaabi A, Al-Rahmani A (2018) Effect of Magnesium Sulfate on Mitochondrial Oxygen Consumption Rate In vitro Study. J Bioanal Biomed 10: 60-63. doi:10.4172/1948593X.1000206

Copyright: @ $2018 \mathrm{Al}$ Zaabi A, et al. This is an open-access article distributed under the terms of the Creative Commons Attribution License, which permits unrestricted use, distribution, and reproduction in any medium, provided the original author and source are credited. 
The Pd phosphor solution $(2.5 \mathrm{mg} / \mathrm{mL}=2 \mathrm{mM})$ was made in $\mathrm{dH} 2 \mathrm{O}$ and stored at $-20^{\circ} \mathrm{C}$ in small aliquots. the $\mathrm{pH}$ was adjusted to $\sim 7.0$ with $12 \mathrm{~N} \mathrm{HCl}$ and stored at $-20^{\circ} \mathrm{C}$. PBS with and without $5 \mathrm{mM}$ glucose stored at $4^{\circ} \mathrm{C}$. Cellular respiration measured in $1 \mathrm{~mL}$ sealed vials containing PBS (with and without $5 \mathrm{mM}$ glucose), $3 \mu \mathrm{M}$ Pd phosphor, and $0.5 \%$ fat-free albumin.

\section{Foreskin specimens}

Sample collection from participants was approved by the $\mathrm{Al}$ Ain Medical District Human Research Ethics Committee (Protocol No. 11/59, approved on 16 April 2012; "The phosphorescence oxygen analyzer as a screening tool for metabolic disorders"). Informed consent obtained from each patient.

\section{Oxygen instrument}

The rate of cellular respiration was determined using phosphorescence analyzer that measures the concentration of dissolved $\mathrm{O}_{2}$ as a function of time $[13,14]$. The Pd phosphor had a maximum absorption at $625 \mathrm{~nm}$ and a maximum phosphorescence emission at $800 \mathrm{~nm}$.

The samples exposed to light flashes (10 per sec) from a pulsed lightemitting diode array that peaked at $625 \mathrm{~nm}$. Emitted phosphorescent light was filtered at $800 \mathrm{~nm}$ and detected by Hamamatsu photomultiplier tube. Amplified phosphorescence was digitized at 1-2 $\mathrm{MHz}$ using an analogue/digital converter (PCI-DAS 4020/12 I/O Board) with 1 to 20 $\mathrm{MHz}$ outputs. Pulses captured at $1.0 \mathrm{MHz}$ [13].

The phosphorescence decay rate characterized by a single exponential; $\mathrm{I}=\mathrm{Set} / \tau$, where $\mathrm{I}=\mathrm{Pd}$ phosphor phosphorescence intensity. The values of $1 /$ were linear with dissolved $\mathrm{O}_{2}: \mathrm{k}_{\mathrm{q}}\left[\mathrm{O}_{2}\right]$, where $1 / \tau=$ the phosphorescence decay rate in the presence of $\mathrm{O}_{2}, 1 / \tau^{\circ}=$ the phosphorescence decay rate in the absence of $\mathrm{O}_{2}$, and $\mathrm{k}_{\mathrm{q}}=$ the secondorder $\mathrm{O}_{2}$ quenching rate constant in $\sec ^{-1} \mu \mathrm{M}^{-1}$ [14].

Cellular respiration measured in $1 \mathrm{~mL}$ vials sealed from air. The vials contained PBS (with and without $5 \mathrm{mM}$ glucose), $3 \mu \mathrm{M}$ Pd phosphor, and $0.5 \%$ fat-free albumin. The temperature was controlled by a circulating water bath (Precision $\pm 0.5^{\circ} \mathrm{C}$ ). $\mathrm{O}_{2}$ concentration, calculated using the equation: $\mathrm{k}_{\mathrm{q}}\left[\mathrm{O}_{2}\right][14]$, decreased linearly with time, indicating the kinetics of mitochondrial $\mathrm{O}_{2}$ consumption was zero-order. The rate of respiration ( $\mathrm{k}$, in $\mu \mathrm{M} \mathrm{O} 2 / \mathrm{min}$ ) was, thus, the negative of the slope $\mathrm{d}\left[\mathrm{O}_{2}\right] / \mathrm{dt}$. A program was developed using Microsoft Visual Basic 6, Microsoft Access Database 2007, and Universal Library components [13]. Magnesium sulfate injected into the vials at $60 \mathrm{~min}$ of respiration at different doses of $10 \mu \mathrm{g}, 5 \mu \mathrm{g}$ and $2.5 \mu \mathrm{g}$ ( stock conc. $50 \mathrm{mg} / \mathrm{ml}$ ).

\section{Statistical analysis}

Data were analyzed using SPSS statistical package (version 19). The nonparametric test ( 2 independent variables) Mann-Whitney was used to compare treated and untreated sample.

\section{Results}

Our study demonstrates a dose dependent reduction of cellular Respiratory rate with the addition of Magnesium Sulfate (Figure 1A-C).

We compared the slope of cellular respiration at base line and then after adding Magnesium sulfate at increasing dosages (5 and $10 \mu \mathrm{M}$ respectively).

We demonstrated a significantly reduced slope of cellular respiration with increasing dose of $\mathrm{Mg}$ Sulfate $(\mathrm{P}<0.001$, for both 5 $\mu \mathrm{M}$ and $10 \mu \mathrm{M}$ in comparisson to baseline) (Figure 2).

\section{Discussion}

Magnesium Sulfate $\left(\mathrm{MgSO}_{4}\right)$ when given to mother $24 \mathrm{~h}$ prior to the delivery of a preterm infant, was reported to reduce mortality in addition to a favorable effect of improving neurological outcome, reduces gross motor dysfunction evident a 2 years evaluation [15].

A major research challenge remains, that is to develop effective methods to limit or prevent perinatal neuronal damage and reduce the severity or prevalence of cerebral palsy and associated co-morbidities following preterm births, and in infants who are exposed to a Hypoxic ischemic insult in the perinatal period [4].

There is increasingly encouraging evidence that $\mathrm{MgSO}_{4}$ is neuroprotective in mature rat pups when given after experimental focal

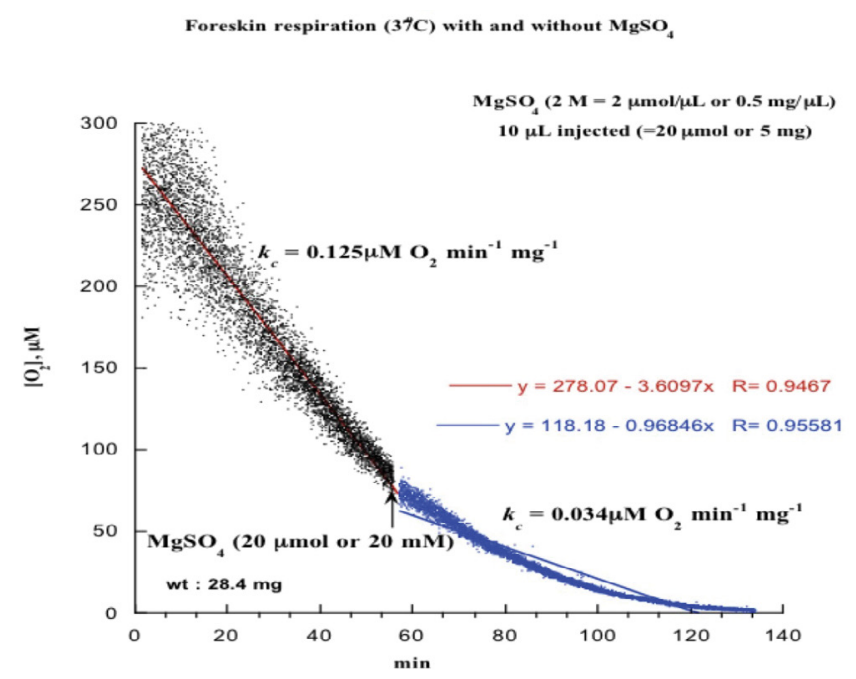

Shows the rate of cellular respiration $(k)\left(\mu \mathrm{M} \mathrm{O}_{2} \mathrm{~min}^{-1} \mathrm{mg}^{-1}\right.$ before addition of $\mathrm{MgSO}_{4} k_{c}=0.125 \mu \mathrm{M} \mathrm{O}_{2} \mathrm{~min}^{-1} \mathrm{mg}^{-1}$. Then after $\mathrm{MgSO}_{4}$ was injected at a dose of $10 \mu \mathrm{L}(=20 \mu \mathrm{M}$ or $5 \mathrm{mg})$, the cellular respiration slope $\left(k_{c}\right)$ was significantly reduced to $0.034 \pm 0.008 \mu \mathrm{M} \mathrm{O}_{2} \mathrm{~min}^{-1} \mathrm{mg}^{-1}(\mathrm{n}=11, \mathrm{P}<.001)$.

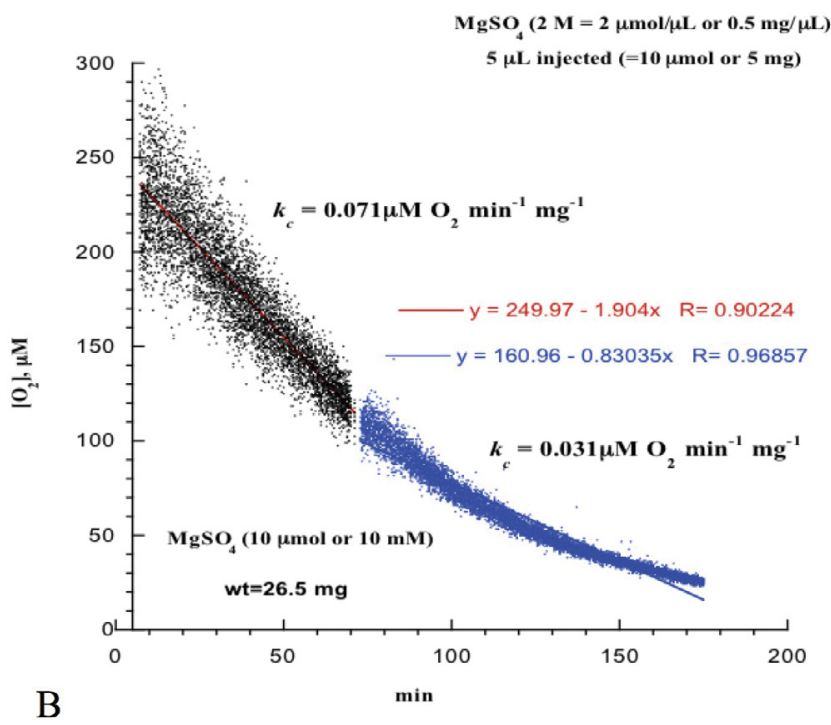

Shows the effect of lower dose of $\mathrm{MgSO}_{4}$ at $5 \mu \mathrm{L}(=10 \mu \mathrm{M}$ or $2.5 \mathrm{mg})$ on the rate of cellulrar respiration $\left(k_{c}\right)$ from a mean baseline cellural respiration slope $\left(k_{c}\right)$ of $0.071 \pm 0.05 \mu \mathrm{M} \mathrm{O}_{2} \mathrm{~min}^{-1} \mathrm{mg}^{-1}$, to a $\left(k_{c}\right)$ rate of $0.031 \pm \mu \mathrm{M} \mathrm{O}_{2} \mathrm{~min}^{-1}$ $\mathrm{mg}^{-}(\mathrm{n}=10, p<0.001)$. 


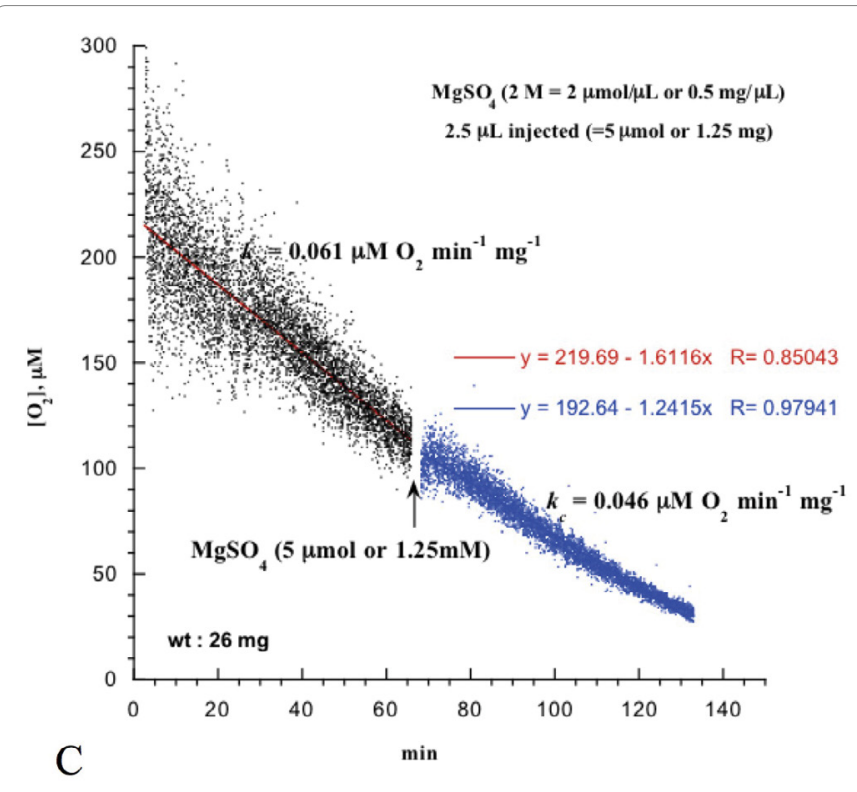

Shows the effect of injecting a lower $\mathrm{MgSO}_{4}$ dose at $2.5 \mu \mathrm{L}(=5 \mu \mathrm{M}$ or 1.25 $\mathrm{mg})$. The mean baseline cellural respiration slope $\left(k_{c}\right)$ was $0.061 \pm 0.017 \mu \mathrm{M}$ $\mathrm{O}_{2} \mathrm{~min}^{-1} \mathrm{mg}^{-}$Then cellural respiration slope $\left(k_{\mathrm{c}}\right)$ significantly reduced to rate of $0.046 \mu \mathrm{M} \mathrm{O}_{2}$ min $^{-1} \mathrm{mg}^{-}(\mathrm{n}=10, \mathrm{P}<0.001)$.

Figure 1: Figures shows that the cellular Respiratory rate $\left(k_{c}\right)$ reduction in a dose-dependent manner. The rate of respiration $\left(k_{\mathrm{c}}\right)$ was reduced with increasing the dose of $\mathrm{MgSO}_{4}$.

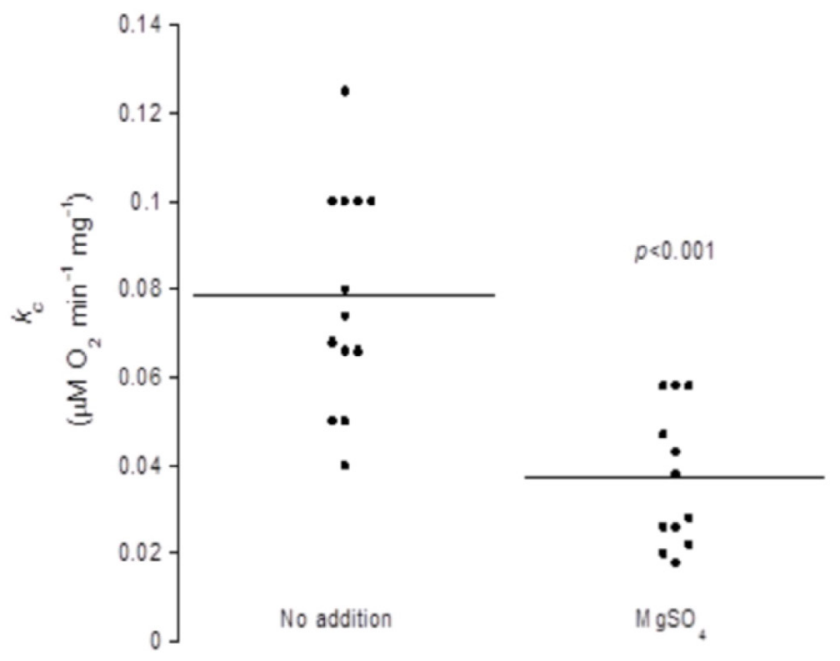

Figure 2: Cumulative analysis of cellular respiratory rate before and after addition of $\mathrm{MgSO}_{4}$ collectively yielding a $(k)$ value of $0.08 \mu \mathrm{M} \mathrm{O}_{2} / \mathrm{min} \mu \mathrm{M} \mathrm{O}_{2}$

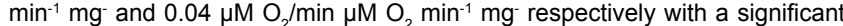
$P$ value of $<0.001$

stroke lesions with an effect that is dose dependent, and a response proven to be more neuroprotective in higher doses of $\mathrm{MgSO}_{4}$.

There are no published studies in human subjects evaluating the combined efficacy of therapeutic hypothermia in the treatment of Hypoxic ischemic encephalopathy (HIE) in the neonatal period. As Therapeutic Hypothermia is emerging as a standard of care treatment for neonatal HIE (NRP reference), the added benefits of magnesium Sulfate in perinatal Hypoxic ischemic insult was not studied [16]. There are animal studies that evaluated neuronal injury reduction with
$\mathrm{MgSO}_{4}$ in adult rats, where pre-treatment with $\mathrm{MgSO}_{4}$ before global cerebral ischemia [17], combined with mild spontaneous hypothermia after ischemia, reduced hippocampal neuronal loss more than $\mathrm{MgSO}_{4}$ or hypothermia alone [18] Thus, combination therapy is promising, but it has not yet been tested in neonatal HIE. One multicenter clinical trial studying the safety and efficacy of hypothermia with $\mathrm{MgSO}_{4}$ (Mag Cool) is currently listed on Clinical Trials Gov. [16].

The results of this study demonstrated a significant $(\mathrm{P}<0.01)$ reduction in foreskin cellular respiration (as a cellular surrogate for the neonatal living cells) with an addition of $\mathrm{MgSO}_{4}$. This effect of $\mathrm{MgSO}_{4}$ was dose dependent whereas the concentration of $\mathrm{MgSO}_{4}$ increased in the studied tissue, the cellular respiration (as reflected by oxygen consumption) decreased by $50 \%$ from the cellular respiration baseline in tissue samples, which were not treated with $\mathrm{MgSO}_{4}$ [19].

The major limitation of this study was the inability unable to run same samples of the foreskin with different drug concentration due to limited cellular viability over a short period. Therefore an alternative approach was followed utilizing one concentration of $\mathrm{MgSO}_{4}$ for each set of sample, then to compare the cellular respiration mean values of each group of samples to the other groups which were treated with different doses.

The results of this novel in vitro study in human cells may indicate that infants who are exposed to treatment with $\mathrm{MgSO}_{4}$ may have similar systemic and cerebral hemodynamics; nevertheless, the Neuroprotection properties of $\mathrm{MgSO}_{4}$ are excreted by lowering the cerebral fractional tissue oxygen extraction cFTOE compared to nontreated controls. These findings also suggest that similar reduction in cerebral metabolism may be a component of the neuroprotective action of antenatal administered $\mathrm{MgSO}_{4}[20]$.

We previously reported a similar experimental method studying neonatal foreskin cellular respiration. Demonstrating that neonatal cellular respiration is highly sensitive to critical temperatures $\left(33^{\circ} \mathrm{C} v s\right.$. $\left.35^{\circ} \mathrm{C}\right)[1]$.

\section{References}

1. Al Zaabi A, Rahmani AY, Souid A (2014) Optimal temperature for whole-body hypothermia in the newborn: an in vitro study using foreskin mitochondrial oxygen consumption. J Neonatal Perinatal Med 7: 179-183.

2. Gathwala G, Khera A, Singh J, Balhara B (2010) Magnesium for neuroprotection in birth asphyxia J Pediatr Neurosci 5: 102-104.

3. Cetinkaya M, Alkan T, Ozyener F, Kafa IM, Kurt MA, et al. (2011) Possible neuroprotective effects of magnesium sulfate and melatonin as both pre- and posttreatment in a neonatal hypoxic-ischemic rat model. Neonatology 99: 302-310.

4. Khashaba MT, Shouman BO, Shaltout AA, Al-Marsafawy HM, Abdel-Aziz $\mathrm{MM}$, et al. (2006) Excitatory amino acids and magnesium sulfate in neonatal asphyxia. Brain Dev 28: 375-379.

5. Bhat MA, Charoo BA, Bhat JI, Ahmad SM, Ali SW, et al. (2009) Magnesium sulfate in severe perinatal asphyxia: a randomized, placebo-controlled trial. Pediatrics 123: e764-e769.

6. McIntyre S, Novak I, Cusick A (2010) Consensus research priorities for cerebra palsy: a Delphi survey of consumers, researchers, and clinicians. Dev Med Child Neurol 52: 270-275.

7. Shokry M, Elsedfy GO, Bassiouny MM, Anmin M, Abozid H (2010) Effects of antenatal magnesium sulfate therapy on cerebral and systemic hemodynamics in preterm newborns. Acta Obstet Gynecol Scand 89: 801-806.

8. Haramati O, Mane R, Molczadzki G, Perez-Polo JR, Chalifa-Caspi V, et al. (2010) Magnesium sulfate treatment alters fetal cerebellar gene expression responses to hypoxia. Int J Dev Neurosci 28: 207-216.

9. Oddie S, Tuffnell DJ, McGuire W (2015) Antenatal magnesium sulfate: Neuro-protection for preterm infants. Arch Dis Child Fetal Neonatal Ed 100: F553-F557. 
Citation: Al Zaabi A, Al-Rahmani A (2018) Effect of Magnesium Sulfate on Mitochondrial Oxygen Consumption Rate In vitro Study. J Bioanal Biomed 10: 60-63. doi:10.4172/1948-593X.1000206

10. Groenendaal F, Rademaker CM, Toet MC, de Vries LS (2002) Effects of magnesium sulphate on amplitude-integrated continuous EEG in asphyxiated term neonates. Acta Paediatr 91: 1073-1077.

11. Al-Jasmi F, Pramathan T, Swid A, Sahari B, Penefsky HS (2013) Mitochondria oxygen consumption by foreskins and fibroblasts. Sultan Qaboos Univ Med J 13: $411-416$

12. Al-Jasmi F, Penefsky HS, Souid AK (2003) The phosphorescence oxygen analyzer as a screening tool for disorders with impaired lymphocyte bioenergetics. Mol Genet Metab 104: 529-536.

13. Shaban S, Marzouqi F, Al Mansouri A, Penefsky HS, Souid AK (2010) Oxygen measurements via phosphorescence. Comput Methods Programs Biomed 100: 265-268.

14. Lo LW, Koch CJ, Wilson DF (1996) Calibration of oxygen-dependent quenching of the phosphorescence of Pd-meso-tetra (4-carboxyphenyl) porphine: a phosphor with general application for measuring oxygen concentration in biological systems. Anal Biochem 236: 153-160.

15. Crowther CA, Hiller JE, Doyle LW, Haslam RR (2003) Effect of magnesium sulfate given for neuroprotection before preterm birth: a rando- mized controlled trial. JAMA 290: 2669-2676.
16. Marinov MB, Harbaugh KS, Hoopes PJ, Pikus HJ, Harbaugh RE (1996) Neuroprotective effects of preischemia intraarterial magnesium sulfate in reversible focal cerebral ischemia. J Neurosurg 85: 117-124.

17. Galinsky R, Bennet L, Groenendaal F, Lear CA, Tan S, et al. (2014) Magnesium Is Not Consistently Neuroprotective for Perinatal Hypoxia-Ischemia in TermEquivalent Models in Preclinical Studies: A Systematic Review. Dev Neurosci 36: 73-82.

18. Zhu H, Meloni BP, Moore SR, Majda BT, Knuckey NW (2004) Intravenous administration of magnesium is only neuroprotective following transient global ischemia when present with post-ischemic mild hypothermia. Brain Res 1014 53-60.

19. Zhu H, Meloni BP, Bojarski C, Knuckey MW, Knuckey NW (2015) Postischemic modest hypo- thermia ( 35 degrees $C$ ) combined with intra- venous magnesium is more effective at reduc- ing CA1 neuronal death than either treatment used alone following global cerebral ischemia in rats. Exp Neurol 193: 361-368.

20. Stark MJ, Hodyl NA, Andersen CC (2015) Effects of antenatal magnesium sulfate treatment for neonatal neuro-protection on cerebral oxygen kinetics. Pediatr Res 78: 310-314 